\title{
ESTIMATING THE PREDICTED RESPONSE TO $S$, FAMILY SELECTION
}

\author{
J. E. BRADSHAW \\ Scottish Crop Research Institute, Pentlandfield, Roslin, Midlothian EH25 9RF, Scotland. \\ received $14 . \mathrm{ii} .83$
}

\begin{abstract}
SUMMARY
It is not possible to estimate the predicted response to $S_{1}$ family selection from the genetical variance between $S_{1}$ family means, nor do estimates of the additive genetic variance and the dominance variance help, as the numerator of the response formula is $\sum 2 p q \alpha \alpha_{s}$. Once it is appreciated that this term is twice the genetical covariance between either half-sib and $S_{1}$ or full-sib and $S_{1}$ family means, practical methods of estimating the response are obvious.
\end{abstract}

\section{INTRODUCTION}

Population improvement by recurrent selection is an important component of breeding programmes with naturally cross-fertilising plants, whether the aim is open-pollinated, synthetic or hybrid cultivars. With characters of low heritability, improvement is faster with family selection than with single plant selection because replicated trials allow the effects of environmental and genotype $x$ environmental interaction variation to be reduced. In plant species, such as maize (Zea mays L.), which can be easily selfed by the breeder, $S_{1}$ family selection is possible.

In recent years, as a result of theoretical and computer simulation studies, a number of authors have advocated $S_{1}$ family selection in preference to other forms of family selection (Wricke, 1976; Choo and Kannenberg, 1979; Wright, 1980). However, before using this method on a particular population of interest, a breeder would wish to estimate the predicted response to selection, and to compare it with those of other possible methods, such as full-sib (FS) and half-sib (HS) family selection. The formula for the predicted response to $S_{1}$ family selection was derived by Empig, Gardner and Compton (1972), for an additive-dominance genetical model, for theoretical purposes and hence no explanation was given of how to estimate the predicted response in practice. Indeed, this is not obvious as the numerator of the formula was expressed as the additive genetic variance plus a complicated component which is mainly a function of the degree of dominance. The formula was extended to include epistasis by Wright (1980), again for theoretical purposes without explanation of how to estimate the response in practice. Although the numerator was expressed as a genetical covariance, it is not immediately obvious that it is twice the genetical covariance between either HS and $S_{1}$ family means or FS and $S_{1}$ family means. Once this is appreciated, practical methods of estimating the predicted response follow. The purpose of this short note is to clarify these points. 


\section{THEORY AND DISCUSSION}

The expected response to $S_{1}$ family selection, with large families or where residual seed of the selected families is used to produce the next cross-pollinated generation, for an additive-dominance genetical model with diploid inheritance and two alleles per locus (frequencies $p, q$ ), is:

$$
\boldsymbol{R}_{\left(\mathbf{s}_{1}\right)}=\frac{i \sum 2 p q \alpha \alpha_{s}}{\sigma_{\mathrm{P}\left(\mathbf{s}_{1}\right)}}
$$

where: $R$ is the change in population mean between cross-pollinated generations, $i$ is the intensity of selection, summation is over loci, $\alpha=$ $a+(q-p) d$ and $\alpha_{s}=a+\frac{1}{2}(q-p) d, 2 a$ is the difference between the two homozygotes and $d$ is the deviation of the heterozygote from the mean of the homozygotes, and $\sigma_{\mathrm{P}\left(\mathrm{S}_{1}\right)}$ is the observed standard deviation of the phenotypic differences between $S_{1}$ family means.

In order to estimate $R_{\left(\mathbf{s}_{1}\right)}$, it is necessary to estimate $\sum 2 p q \alpha \alpha_{s}$, but this is not possible from the genetical variance between $S_{1}$ family means, nor would estimates of the additive genetic variance $\left(\sum 2 p q \alpha^{2}\right)$ and the dominance variance $\left(\sum(2 p q d)^{2}\right)$ help unless $p=q=\frac{1}{2}$ or $d=0$ at all loci, in which case $\sum 2 p q \alpha \alpha_{s}=\sum 2 p q \alpha^{2}=\sum 2 p q a^{2}$. This can be seen as follows:

$$
\begin{aligned}
\sum 2 p q \alpha \alpha_{s} & =\sum 2 p q\left[\alpha^{2}+\left(p-\frac{1}{2}\right) d \alpha\right] \\
& =\sum 2 p q \alpha^{2}+\sum 2 p q \alpha\left(p-\frac{1}{2}\right) d
\end{aligned}
$$

the genetical variance between $\mathrm{S}_{1}$ family means

$$
\begin{aligned}
=\sum 2 p q \alpha_{s}^{2} & +\frac{1}{4} \sum(2 p q d)^{2} \\
=\sum 2 p q \alpha^{2} & +\frac{7}{4} \sum(2 p q d)^{2} \\
& -\frac{3}{2} \sum p q d^{2}-2 \sum p q(q-p) a d .
\end{aligned}
$$

Hence estimates of the predicted response to $S_{1}$ family selection which use $\sum 2 p q \alpha^{2}, \sum 2 p q \alpha_{s}^{2}$ or $\sum 2 p q \alpha_{s}^{2}+\frac{1}{4} \sum(2 p q d)^{2}$ in place of $\sum 2 p q \alpha \alpha_{s}$ are biased, as has been recognised by a number of authors (Jan-orn et al., 1976; Eckebil et al., 1977; Choo and Kannenberg, 1981).

However, it can be shown from table 1 that the genetical covariance between $\mathrm{HS}$ and $\mathrm{S}_{1}$ family means equals $\frac{1}{2} \sum 2 p q \alpha \alpha_{s}$, a point not made in the textbooks by Falconer (1981), Hallauer and Miranda (1981) and Mather and Jinks (1982). Similariy the genetical covariance between FS and $S_{1}$ family means equals $\frac{1}{2} \sum 2 p q \alpha \alpha_{s}$. Once this is appreciated a number of practical methods of estimating $\sum 2 p q \alpha \alpha_{s}$ are obvious. Although attention will be confined to maize (Zea mays L.), the methods can be used with other naturally cross-fertilising plant species which can be easily selfed by the breeder.

In a population of prolific (two-eared) plants the lower ears in a row of plants can be selfed, the plants detasselled and the upper ears allowed to be naturally cross-pollinated by an adjacent row of plants from the population, in order to produce the corresponding half-sib families. The $\mathrm{HS}, \mathrm{S}_{1}$ covariance table shows that the covariance is not affected by variation in the allele frequency in the pollen, as a result of the pollen coming from only a few plants, provided that on average the frequency equals the population frequency for the various genetical types of "common maternal 
TABLE 1

Table for calculating the $H S, S_{1}$ covariance for a single locus

\begin{tabular}{|c|c|c|c|}
\hline $\begin{array}{l}\text { Female } \\
\text { parent }\end{array}$ & Frequency & HS means & $\mathrm{S}_{1}$ means \\
\hline \multirow[t]{2}{*}{ AA } & $p^{2}$ & $\frac{a}{l} \sum_{i=1}^{l} p_{i}+\frac{d}{l} \sum_{i=1}^{l} q_{i}$ & $a$ \\
\hline & \multicolumn{3}{|c|}{$=a p+d q$} \\
\hline \multirow[t]{2}{*}{ Aa } & $2 p q$ & $\frac{a}{2 m}\left(\sum_{j=1}^{m} p_{j}-\sum_{j=1}^{m} q_{i}\right)+\frac{1}{2} d$ & $\frac{1}{2} d$ \\
\hline & \multicolumn{3}{|c|}{$=\frac{1}{2} a(p-q)+\frac{1}{2} d$} \\
\hline \multirow[t]{2}{*}{ aa } & $q^{2}$ & $-\frac{a}{n} \sum_{k=1}^{n} q_{k}+\frac{d}{n} \sum_{k=1}^{n} p_{k}$ & $-a$ \\
\hline & \multicolumn{3}{|c|}{$=-a q+d p$} \\
\hline mean & 1 & $(p-q) a+2 p q d$ & $(p-q) a+p q d$ \\
\hline \multicolumn{4}{|c|}{$\begin{array}{l}\left.\text { covariance (HS, } \mathrm{S}_{1}\right)=p q[a+(q-p) d]\left[a+\frac{1}{2}(q-p) d\right]=p q \alpha \alpha_{s} \\
\quad l, m \text { and } n \text { are the number of plants of type AA, Aa and aa respectively which } \\
\text { are selfed and } p_{i}, p_{i} \text { and } p_{k} \text { are the frequencies of the } \mathrm{A} \text { allele in the pollen used to } \\
\text { produce the half-sib families on these same } l, m \text { and } n \text { plants respectively. }\end{array}$} \\
\hline
\end{tabular}

parent". (In contrast the variance of such HS families is inflated by such variation in allele frequency in the pollen and contains dominance variance as well as additive genetic variance.) In the extreme case of the pollen coming from a single plant one has FS families (parents (1) and (2)). Indeed, the upper ears could be pollinated by the breeder in this way to produce the corresponding full-sib families and the covariance $\left(F S, S_{1}(1)\right)$ estimated. If these single plants are also selfed the covariance (FS, $\left.\left[S_{1}(1)+S_{1}(2)\right] / 2\right)$ can be estimated, and if the reciprocal crosses are also made, one has the augmented biparental mating scheme of Kearsey (1970).

In a population of non-prolific plants, plants could be selfed and crossed, as males, to other plants chosen at random from the population. Although it would be sufficient to cross each plant to just one other plant to estimate the covariance (FS, $\left.S_{1}(2)\right)$, it would be sensible to cross each plant to a number of other plants according to the design I mating scheme of Comstock and Robinson (1948), in order to also estimate the additive.genetic variance and the dominance variance. This would allow $S_{1}$ family selection to be compared with other possible methods such as HS and FS family selection.

If having produced these $H S$ and $S_{1}$ or FS and $S_{1}$ families they are independently randomised in the assessment trial, so that they do not share a common environment, their phenotypic covariance will equal the genetic covariance, and twice this covariance equals $\sum 2 p q \alpha \alpha_{s}$.

Acknowledgements. I thank Drs F. J. W. England and P. D. S. Caligari for helpful discussions.

\section{REFERENCES}

CHOO, T. M. AND KANNENBERG, L. W. 1979. Relative efficiencies of population improvement methods in corn: a simulation study. Crop Science, 19, 179-185. 
CHOO, T. M. AND KANNENBERG, L. W. 1981. Comparison of predicted and simulated responses to $S_{1}$ selection in a diploid, cross-fertilized species. Canadian Journal of Plant Science, 61, 9-15.

COMSTOCK, R. E. AND ROBINSON, H. F. 1948. The components of genetic variance in populations of biparental progenies and their use in estimating the average degree of dominance. Biometrics, 4, 254-266.

ECKEBIL, J. P., ROSS, W. M., GARDNER, C. O. AND MARANVILLE, J. W. 1977. Heritability estimates, genetic correlations, and predicted gains from $S_{1}$ progeny tests in three grain sorghum random-mating populations. Crop Science, 17, 373-377.

EMPIG, L. T., GARDNER, C. O. AND COMPTON, W. A. 1972. Theoretical gains for different population improvement procedures. Nebraska Agricultural Experiment Station Bulletin 26 (Revised).

FALCONER, D. S. 1981. Introduction to Quantitative Genetics, 2nd edition. Longman, London and New York.

HALlAUER, A. R. AND MIRANDA, J. B. 1981. Quantitative Genetics in Maize Breeding. Iowa State University Press, Ames.

JAN-ORN, J., GARDNER, C. O. AND ROSS, W. M. 1976. Quantitative genetic studies of the NP3R random-mating grain sorghum population. Crop Science, 16, 489-496.

KEARSEY, M. J. 1970. Experimental sizes for detecting dominance variation. Heredity, 25, 529-542.

MATHER, K. AND JINKS, J. L. 1982. Biometrical Genetics, 3rd edition. Chapman and Hall, London and New York.

WRICKE, G. 1976. Comparison of selection based on yield of half sib progenies and of $I_{1}$ lines per se in rye (Secale cereale L.). Theoretical and Applied Genetics, 47, 265-269.

WRIGHT, A. J. 1980. The expected efficiencies of half-sib, testcross and $S_{1}$ progeny testing methods in single population improvement. Heredity, 45, 361-376. 